\section{G184(P) HOSPITAL CLASSROOMS: A NOVEL CONCEPT IN THE DEVELOPING WORLD}

S Sen, A Deshpande, P Gadgil, T Singhal. Department of Paediatrics, Kokilaben Dhirubhai Ambani Hospital, Mumbai, India

\subsection{6/archdischild-2018-rcpch. 179}

Introduction Though most tertiary paediatric centres in UK have been running hospital schooling programmes for years, the idea is almost non existent in developing countries. It seems that schooling hospitalised children is either non existent or forgotten, or remains a very low priority for families in the developing world. Even where it does exist, most parents, attending doctors and health care staff seems to be unaware of its benefits. Education is a fundamental right of all children including those in a hospital.

Place of study We are a tertiary paediatric centre, amongst the first in the sub-continent to start a hospital teaching programme with specially appointed teaching staff.

Outcome The initial response to this initiative was not very encouraging with an average daily attendance of $5.6 \%$ of admitted children. Overtime it has improved but still remains to less than $16 \%$ of admitted children. $92 \%$ of children attending the classroom are between 4 to 7 years of age. Children above 10 years were reluctant to attend and surprisingly their parents also supported them. When we tried to ascertain the reasons for the reluctance, $71 \%$ stated that their child is resting and needs to recover and $62 \%$ stated that they do not want to burden their children with studies during illness. When we looked at awareness about the existing hospital teaching programme, $55 \%$ of the attending health care workers including doctors and nurses throughout the hospital were not aware of such an initiative provided by the hospital and $85 \%$ of parents were unaware about such facilities provided by the hospital. We are now in the process of remedying this deficiency with parental and staff awareness programmes. Till date hospital classroom initiative has helped us to identify 14 cases of learning difficulties.

Conclusion As paediatricians, we should take responsibility to ensure that all children have access to appropriate education, even while they are hospitalised. For children undergoing treatment, school can offer a familiar and reassuring routine, as well as a feeling of being in step with their peers in the outside world. This concept needs to be popularised further specially in the developing world.

\section{G185(P) DESIGNING TRANSFORMATIVE OSCES: LESSONS FROM AN ADOLESCENT SMOKING CESSATION STATION}

1. Peppas, ${ }^{2} \mathrm{EJA}$ Fitchett, 'W Kenworthy, ${ }^{1} \mathrm{P}$ Kimkool, ${ }^{1} \mathrm{CR}$ Fertleman. 'Department of Paediatrics, Whittington Health, London, UK; ${ }^{2}$ Institute of Child Health, Great Ormond Street Hospital, London, UK

\subsection{6/archdischild-2018-rcpch.180}

Background Working with patients to improve medical education can help align training with real clinical practice and empower patients to influence attributes of newly qualified doctors, including their communication skills. The benefits of effective patient-centred communication include higher patient and doctor satisfaction, shared decision making, treatment adherence and improved health outcomes. Half of the most common health problems in adults arise from behaviours that are established during adolescence; $40 \%$ of adult smokers in the UK starting smoking before the age of 16 years (Rise Above Programme, 2017).

Aim To co-design a transformative OSCE station to assess medical student's ability to motivate adolescents to stop smoking, with adolescent smokers being involved in this process from inception to final assessment.

Methods We organised a workshop with medical educators and adolescent smokers to co-create the consultation narrative for a smoking cessation OSCE. The station was designed to assess the ability of medical students to practice motivational interviewing, a behavioural change technique taught in their curriculum. This OSCE station was included in the summative assessment of 364 penultimate year medical students in 2017. We recruited 12 examiners and 6 adolescent actors for this OSCE station and both examiners and actors gave written feedback to each candidate. We had ethical permission to obtain copies of this information and although we gave the students the option to opt out none did.

Results Although the pass rates were similar amongst different groups, there were significant differences in the scores of students assessed by distinct examiner and role-player combinations. These differences were also reflected by the quality of written feedback provided to students. Importantly, students who received full marks from the adolescent role-player were significantly more likely to get a high overall score in the OSCE station, with substantial agreement between role-players and examiners' marks. Most students (85.7\%) were competent in employing motivational interviewing techniques, but only half were proficient in gathering sufficient information to offer a personalised management plan.

Conclusion Involving adolescent patients in medical education can increase the validity of assessments and assist in identifying ways to further improve the communication skills of medical students.

\section{G186(P) 'PAEDIATRIC PITSTOP' GENERAL ACADEMIC PAEDIATRIC RESEARCH WORKSHOP}

${ }^{1} \mathrm{C}$ Purcell, ${ }^{1} \mathrm{C}$ Martins, IJ Balfe, ${ }^{2} \mathrm{EJ}$ Molloy. ${ }^{1}$ General Paediatrics Department, National Children's Hospital, Tallaght, Dublin, Ireland; ${ }^{2}$ Department of Paediatrics and Trinity Translational Medicine Institute, Trinity College, University of Dublin, Dublin, Ireland

\subsection{6/archdischild-2018-rcpch.18}

Aims Research and audit activity is mandatory for Paediatric trainees with one annual audit the minimum expected standard. Senior support has been shown to be helpful in facilitating successful project completion. With this aim a General Paediatric research workshop was established, providing a supportive forum for discussion and advice on individual projects. This paper will describe the development and outomes of this project.

Methods An open, monthly, Consultant-supported, breakfast meeting was convened facilitating junior doctor attendance. Participants were allocated $5 \mathrm{~min}$ to provide a short focused presentation, noting progress and highlighting difficulties in research projects. Group input and structured feedback was encouraged to optimise ideas and solutions. Deadlines and targeted publications were advised with an aim to ensure project success. Attendances were recorded, weekly logs kept of each project with recommended advice and timelines for completion.

Results 11 workshops have been held to date; involving Consultants, junior hospital doctors, Nurse Specialists, Dieticians 